\title{
PLANIALTIMETRIC EVALUATION OF A CARTOSAT-1 STEREO PAIR - CASE STUDY: SÃO SEBASTIÃO, SP, BRAZIL
}

\author{
R. S. Barros ${ }^{\mathrm{a}}$, C. B. M. Cruz ${ }^{\mathrm{a}}$, L. M. L. Rabaco \\ ${ }^{a}$ Departamento de Geografia, Instituto de Geociências, Universidade Federal do Rio de Janeiro. \\ Rua Athos da Silveira Ramos, 274 - B1. I - Sala 012, CCMN, Cidade Universitária - CEP 21941-590 - Rio de \\ Janeiro, Brasil - (rafael.barros, cmad)@ufrj.br \\ ${ }^{\text {b}}$ CENPES/Petrobras, Av. Horácio de Macedo 950 - Cidade Universitária \\ CEP 21941-915 - Ilha do Fundão - Rio de Janeiro - Brasil - lismaria@ petrobras.com.br
}

\section{Commission IV/3}

Keywords: IRS-P5, DEM/DTM, Orthoimage, Accuracy, Cartography.

\begin{abstract}
:
It is noticed a significant increase in the development of orbital and airborne sensors that enable the extraction of three-dimensional data. So, it's important the increment of studies about the quality of altimetric values derived from these sensors to verify if the improvements implemented in the acquisition of data may influence the results. In this context, as part of a larger project that aims to evaluate the accuracy of various sensors, this work aims to analysis the planialtimetric accuracy of DEM generated from Cartosat-1 stereo pair. The project was developed for an area near the city of São Sebastião, located in the basin of the North Coast of São Paulo state, in Brasil. The relief in this area is very steep, with a predominance of dense forest vegetation, typical of the Atlantic Forest. All points in this assessment have been established in the field, with the use of single frequency (L1) GNSS receivers, through static relative positioning. In this work it was considered the Brazilian standard specifications (PEC, in Portuguese) for classification of cartographic bases. Results may be considered very good and showed that Cartosat-1 orthoimage presents accuracy equivalent to class B for 1:10.000 scale. The DEM presents altimetric accuracy compatible with class A of the 1:25.000 scale. Results obtained are true for this specific area/study case, but may vary in case different scenes or other studies areas are considered.
\end{abstract}

\section{INTRODUCTION}

The improvement of products available to DEM and Orthoimage production is very important for Brasil because it may help cartographic updates, since most of Brazilian maps were generated in the seventies and eighties. For many areas in Brasil, cartography presents a lack of maps in larger and with high details scales.

In this context, Cartosat-1 stereo pairs - or similar ones with a good cost $\mathrm{x}$ benefit relationship - could contribute for cartographic bases production, reaching scales not covered by other sensors.

But since the use of those orbital data is something new, it is important the increment of studies about the quality of altimetric values (and also planimetric data) derived from these sensors in order to verify if the improvements implemented on data acquisition may influence results (Correia, 2008).

Cartographic products in Brasil should be evaluated, considering a norm called Brazilian standard for cartography accuracy (PEC, in Portuguese - Brasil, 1984). This norm specifies that $90 \%$ of the points used in the assessment must present errors and standard deviation till a predetermined threshold (according to the scale). According to errors found, the product may be classified as class A (higher accuracy), B or $\mathrm{C}$ (lower accuracy) for each scale. Table 1 presents the limits of the errors and standard deviation acceptable for scales 1:10,000 and 1:25,000, for planimetry. Table 2 presents the limits of errors and standard deviations for scale 1:25,000 for altimetry.

\begin{tabular}{|l|c|c|c|c|}
\hline & \multicolumn{2}{|c|}{$1: 10,000$} & \multicolumn{2}{c|}{$1: 25,000$} \\
\hline & Tol. (m) & SD (m) & Tol. (m) & SD (m) \\
\hline Class A & 5.0 & 3.0 & 12.5 & 7.5 \\
\hline
\end{tabular}

\begin{tabular}{|l|c|c|c|c|}
\hline Class B & 8.0 & 5.0 & 20.0 & 12.5 \\
\hline Class C & 10.0 & 6.0 & 25.0 & 15.0 \\
\hline
\end{tabular}

Tol.: Tolerance; SD: Standard Deviation; m: meters

Table 1: Limit values used to classify cartographic products according to PEC, for planimetry.

\begin{tabular}{|l|c|c|}
\hline \multicolumn{3}{|c|}{$1: 25,000$} \\
\hline & Tol.(m) & SD $(\mathrm{m})$ \\
\hline Class A & 5.0 & 3.3 \\
\hline Class B & 6.0 & 4.0 \\
\hline Class C & 7.5 & 5.0 \\
\hline
\end{tabular}

Tol.: Tolerance; SD: Standard Deviation; m: meters

Table 2: Limit values used to classify cartographic products according to PEC, for altimetry.

\subsection{Objectives}

In this context, this work aims to analysis the planimetric accuracy of an orthoimage and the altimetric accuracy of a DEM (Digital Elevation Model) generated from a Cartosat-1 stereo pair, considering the Brazilian norm (PEC).

\subsection{Study Area}

The evaluation took place in an area near the municipality of São Sebastião, located in the north coast of São Paulo state (Southeast of Brasil). It is part of a mountains chain called Serra do Mar that presents a great height difference between the top and the bottom (around 1,300 meters) in this area that is quite close to the sea. So, relief of the area is very steep, with a predominance of dense forest vegetation, typical of the Atlantic 
Forest. Figure 1 shows study area and the amount of points used in this assessment.

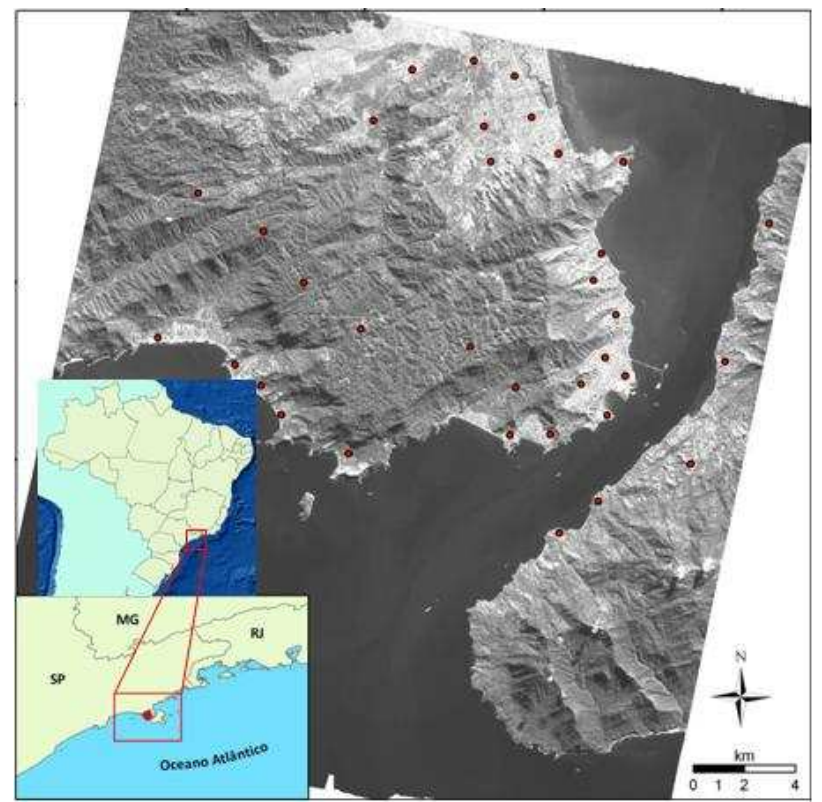

Figure 1: Study area location and points used in the assessment

\subsection{Cartosat-1}

Cartosat-1, also called IRS-P5, is an Indian satellite, launched on May 5th, in 2005 and it presents the capability of acquiring along track stereo images in panchromatic band. Its sensor presents a spatial resolution of 2.5 meters and radiometric resolution of 10 bits. Stereo pair is acquired in 2 different angles: $26^{\circ}$ (forward view) and $5^{\circ}$ (afterward view), which makes it possible to obtain a $\mathrm{B} / \mathrm{H}$ ratio of 0.62 .

\section{MATERIALS AND METHODS}

\subsection{Field Survey}

For this assessment it was necessary to determine coordinates for 39 (thirty nine) points to be used in the geometric modeling process and other points to be used in the accuracy evaluation.

All coordinates were determined in field trips using GNSS single frequency (L1) receivers, through static relative positioning, registering data each 1 second during 30 minutes, obtaining a minimum of 1,500 epochs, for a distance between base and rover receivers not larger than 20 kilometers. All these values are according to Brazilian Institute for Geography and Statistics (IBGE) specifications. In this work comparison results refers to the Brazilian standard specifications (PEC) for classification of cartographic bases.

\subsection{DEM and Orthoimage Generation}

Cartosat-1 stereo pair (Path / Raw: 1814 / 0498) used in this assessment was acquired in May 23 2009, with the orthokit processing level, with RPCs (Rational Polynomial Coefficients). Cartosat-1 DEM and orthoimage were generated in PCI Geomatica Orthoengine 10.2, using RPCs. In order to improve results it was also used 7 (seven) GCP (Ground Control Points) and 8 (eight) Tie Points. The heights of Tie Points were obtained using SRTM DEM. Final RMS was below 2.5 meters.

For DEM generation, data was resampled to 5 meters when Epipolar Images were created and resampled again to 10 meters during DEM generation. Orthoimage was generated with the nominal spatial resolution of the raw data: 2.5 meters.

\subsection{Planimetric Evaluation}

The planimetric evaluation was done comparing coordinates of 30 (thirty) Checkpoints (not used on the DEM and orthoimage generation process), which spatial distribution was presented in figure 1, and its homologues on the orthoimage. Most of Checkpoints were determined in intersections between roads or streets (figure 2).

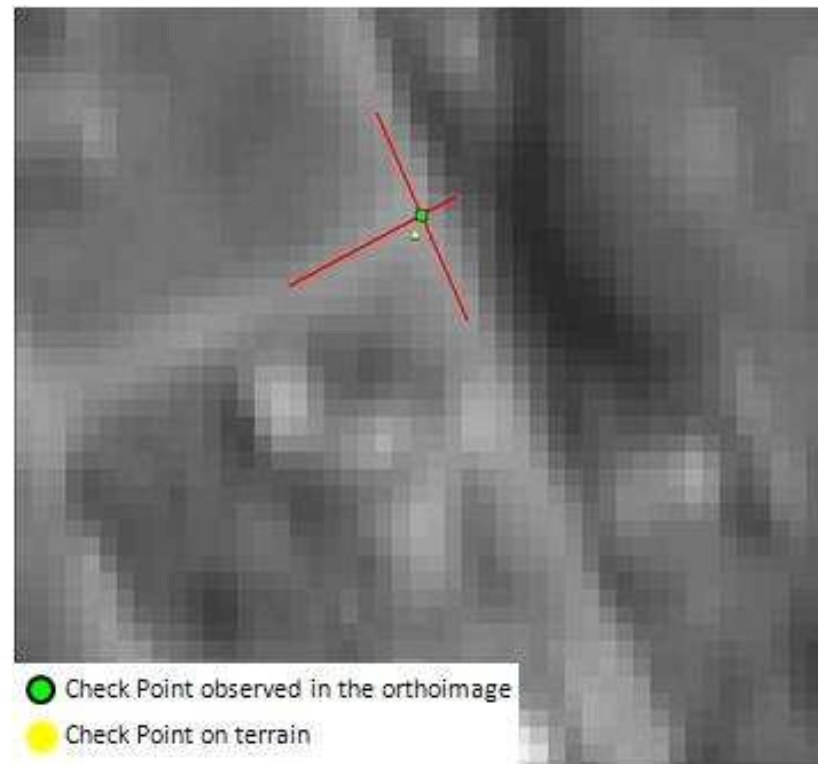

Figure 2: Example of a Check Point

Difference between coordinates (in the orthoimage and on terrain) were calculated, obtaining the Euclidean distance which was considered an error and the errors were analyzed considering the specifications of PEC: at least $90 \%$ of the points used in this evaluation should present errors smaller than values presented in table 1 .

\subsection{Altimetric Evaluation}

For this evaluation it was used 32 (Thirty two) Checkpoints, which spatial distribution was presented in figure 1. Altimetry evaluation was done comparing heights of the 32 Checkpoints with the value obtained in the GNSS survey plus the difference between ellipsoid and geoid in each point. Again results were analyzed considering PEC specification, which limits for error and standard deviation for altimetry are presented in table 2 .

\section{RESULTS}

In General, results may be considered quite good and they are according to results observed on evaluation of equivalent sensors like PRISM (Barros et al. 2009). Results are presented separately, according to the kind of evaluation.

\subsection{Planimetric Evaluation}

Considering the errors estimated for the 30 points used in the assessment, as well as the standard deviation observed (2.651 $\mathrm{m})$, this orthoimage presents planimetric accuracy compatible with the specified for class A of the scale 1:10,000, whose tolerance is 8 meters and the standard deviation limit is 5 meters. We also calculated the Circular Error for $90 \%$ of the points (CE90), obtaining 5.56 meters. Table 3 presents the percentages of Checkpoints presenting error till the limits specified for each accuracy class for 1:10,000 scale.

\begin{tabular}{|c|c|c|c|}
\hline Class & $\begin{array}{c}\text { Tolerance } \\
\text { (meters) }\end{array}$ & $\begin{array}{c}\text { Checkpoint } \\
\text { Number }\end{array}$ & $\begin{array}{c}\text { Percentage } \\
(\%)\end{array}$ \\
\hline
\end{tabular}




\begin{tabular}{|c|c|c|c|}
\hline A & 5,0 & 24 & 80.0 \\
\hline B & 8,0 & 28 & 93.3 \\
\hline C & 10,0 & 29 & 96.7 \\
\hline
\end{tabular}

Table 3: Classification of the results according to the PEC for the scale $1: 10,000$

According to the offset values observed at checkpoints, we calculated the average and standard deviation obtaining 3.49 meters and 2.65 meters, respectively, for the 30 checkpoints used in this evaluation. There appears to be no significant trends in the displacement, since the mean differences in $\mathrm{x}$ and $\mathrm{y}(\mathrm{E}$ and $\mathrm{N}$ ) are $0.11 \mathrm{~m}$ and $0.66 \mathrm{~m}$ respectively. These values are quite low when considering the pixel size (2.5 meters).

Figure 3 shows the distribution of errors (displacement) at each checkpoint. It shows a distribution without major trends, although the largest displacement occurred at a point with high elevation. In the remainder of the area, including other points with higher elevations, results are homogeneous, indicating that the orthorectification was able to correct the relief effect.

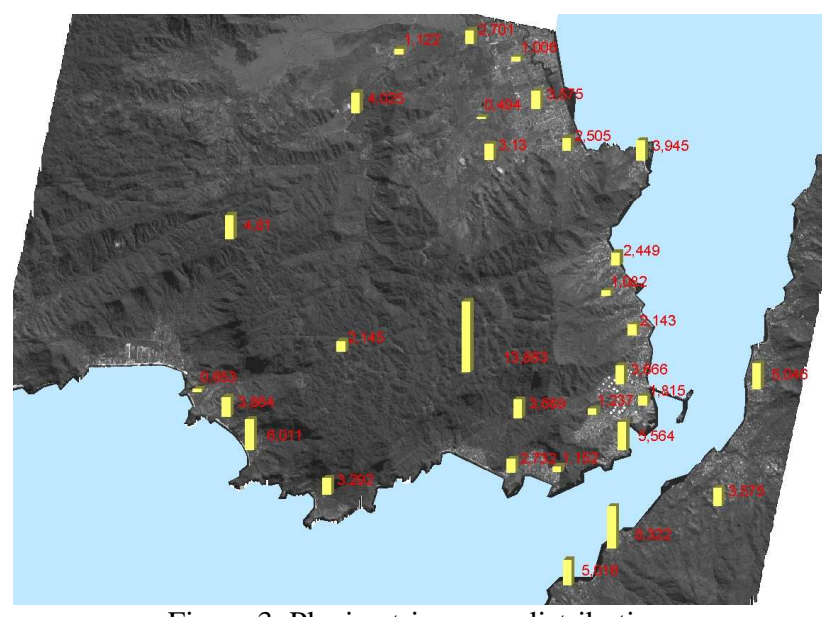

Figure 3: Planimetric errors distribution

\subsection{Altimetric Evaluation}

Considering the tolerances established in the PEC, $94.12 \%$ of the checkpoints presented errors till the limit ( $5 \mathrm{~m}$ tolerance) for class A of the 1:25,000 scale. The standard deviation calculated is also under the limit $(3.3 \mathrm{~m})$ for class A of the same scale. LE90 (Linear Error for $90 \%$ of the points) was calculated, obtaining 3.75 meters. Table 6 below shows how the accuracy of the DEM altimetry can be classified according to the PEC, taking as reference the scale 1:25,000.

\begin{tabular}{|c|c|c|c|}
\hline Class & $\begin{array}{c}\text { Tolerance } \\
\text { (meters) }\end{array}$ & $\begin{array}{c}\text { Checkpoint } \\
\text { Number }\end{array}$ & $\begin{array}{c}\text { Percentage } \\
(\%)\end{array}$ \\
\hline $\mathrm{A}$ & 5.0 & 32 & 94.1 \\
\hline $\mathrm{B}$ & 6.0 & 32 & 94.1 \\
\hline $\mathrm{C}$ & 7.5 & 33 & 97.1 \\
\hline
\end{tabular}

Table 4: Classification of the results according to the PEC for the scale 1:25,000

Just as in the planimetric evaluation, it was observed no significant trend in the altimetric errors, since the average was calculated in $\quad-0.427$ meters. The highest error was 10.073 meters.

Figure 4 shows the distribution of the checkpoints errors. In this figure its possible to observe that, despite the highest error is located in a high altitude area, errors are well distributed, in general.

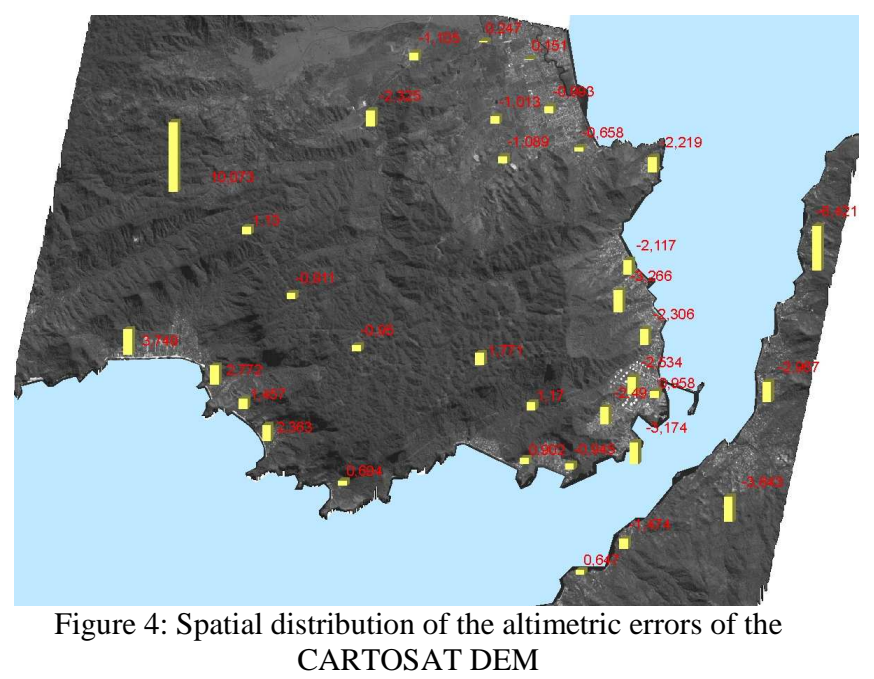

Like any DEM generated by automatic correlation from stereoscopic pairs, there is failure in areas which the correlation is not good. In general these gaps occur in areas with clouds and their shadows, in places where there is a blockage in one (or both) of the scenes of the pair; in very homogeneous area. After verifying that these failure areas occurred where it was foreseeable, the DEM was generated again, using the option to fill the voids and filter results. Figure 5 shows the areas where faults were located in. Most of those failures occured in the southeastern part of the area, probably, because few GCPs were used there.

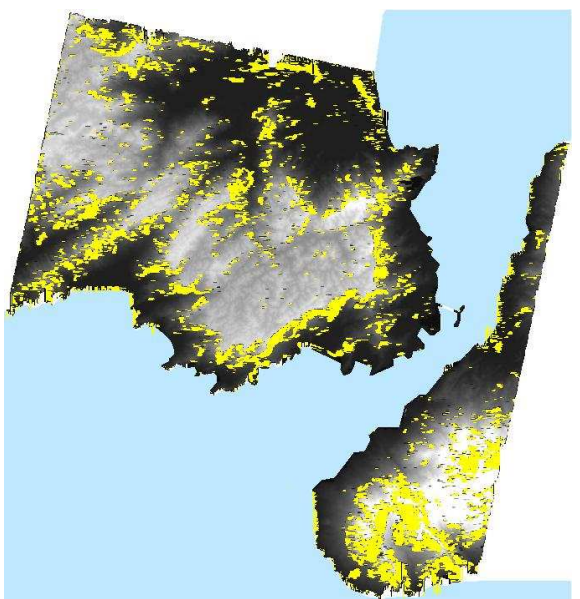

Figure 5: Areas of failure (in yellow) on the CARTOSAT DEM

\section{CONCLUSIONS}

According to the results, CARTOSAT DEM presented planimetric accuracy compatible with the specified to the class $\mathrm{B}$ of the scale 1:10,000 and altimetric accuracy compatible with the specifications for class A of the scale 1:25,000.

The results for the DEM CARTOSAT were according to what is expected for a sensor with its characteristics. Cartography Coordination of IBGE (Brazilian Institute for Geography and Statistics) presented the evaluation of a DEM generated from Triplet data of ALOS/PRISM, which has spatial resolution equal to the CARTOSAT (IBGE, 2009). Results were very similar.

Although in the present work Orthoimage and DEM derived from Cartosat-1 data showed planimetric accuracy compatible 
with the specification for the scale 1:10,000 (class B) and altimetric accuracy compatible with the specified for scale $1: 25,000$ (Class A), it is important to note - as it was highlighted in IBGE (2009) - that orthoimages and DEM derived from this sensor does not allow the extraction of all cartographic features present, typically, in official topographic maps at this scales. The spatial resolution of the original image (2.5 meters) probably does not permit the identification of minor elements. The evaluation effort in this work was focused on assessment of the geometry, both planimetric and altimetric rather than content / semantics of information. So while an assessment focusing on the feature extraction/interpretability of the Cartosat-1 data is not done, it is estimated that its use allows obtaining cartographic features compatible with the scale 1:50,000.

\section{REFERENCES}

\section{References from Journals:}

TOUTIN, T. 2004. Comparison of Stereo-Extracted DTM from Different High-Resolution Sensors: SPOT-5, EROS-A, IKONOS-II, and QuickBird. IEEE Transactions on Geoscience and Remote Sensing. 42(10), pp. 2121-2129.

\section{References from Other Literature}

CORREIA, J. D. (2008). Mapeamento de feições deposicionais quaternárias por imagens orbitais de alta resolução espacial Médio Vale do Paraíba do Sul. Tese Doutorado, IGEO/UFRJ.

\section{References from websites:}

BARROS, R. S.; COELHO, A. L.; OLIVEIRA, L. F.; MELO, M. F.; CORREIA, J. D. Avaliação Geométrica de Imagens ALOS/PRISM Níveis 1B2G e 1B2R Ortorretificada - estudo de caso: Itaguaí, RJ. In: XIV Simpósio Brasileiro de Sensoriamento Remoto (SBSR) 14..2009, Natal. Anais...São José dos Campos: INPE, 2009. Artigos, p. 1243-1250. CDROM, On-line. ISBN 978-85-17-00044-7 . Disponível em: < http://marte.dpi.inpe.br/col/dpi.inpe.br/sbsr@80/2008/11.17.19. 47/doc/1731-1738.pdf>. (20 Nov. 2010).

BRASIL, Decreto 89.817 de 20 de junho de 1984. (1984) Estabelece as Instruções Reguladoras das Normas Técnicas da Cartografia nacional. Diário Oficial da República Federativa do Brasil, Brasília, n120, 22 de junho de 1984. Site: http://www.planalto.gov.br/ccivil_03/decreto/19801989/D89817.htm. (10 Apr. 2012).

IBGE (2009). Avaliação Planialtimétrica de Dados ALOS/PRISM, Estudo de Caso: Itaguaí-RJ. Disponível em: http://www.ibge.gov.br/alos/relatorios.php. (19 Feb. 2010). 